\title{
Portuguese industry and the EU trade emissions directive: development and analysis of $\mathrm{CO}_{2}$ emission scenarios
}

\author{
C. Borrego*, H. Martins, M. Lopes \\ Department of Environment and Planning, University of Aveiro, 3810-193 Aveiro, Portugal
}

\begin{abstract}
In December 1997, the Kyoto Protocol was adopted, setting limits on the greenhouse gas (GHG) emissions of industrialized countries. The European Union agreed to reduce its emissions of GHG by 8\% during the period 2008-2012 in comparison to their 1990 levels. Subsequently, in a scheme known as "burden-sharing", Portugal was allowed to increase its emissions by $27 \%$ in the same period.

Large industrial facilities are responsible for a significant share of carbon dioxide $\left(\mathrm{CO}_{2}\right)$ emissions and are object of a European Directive (2003/87/EC) establishing the scheme for GHG emission allowance trading within the European Union, launched with the purpose of allowing the reduction of GHG emissions cost-effectively. According to the Directive, Member States shall develop a National Allocation Plan (NAP) stating the total quantity of allowances that each one intends to allocate and how it proposes to allocate them among the activities included in the trading scheme.

In this work, an analysis of the Portuguese industry is performed, focused on the energy consumption and $\mathrm{CO}_{2}$ emissions levels in the period 1990-2001 and on the estimation of the two parameters for the period 2002-2012, considering different economic growth scenarios and investments on energy reduction technologies.

Results show that all the analysed sectors present a significant growth in $\mathrm{CO}_{2}$ emissions, exceeding the limit established in the frame of the Kyoto Protocol, and that measures other than cost-effective energy technologies will have to be implemented.

(C) 2004 Elsevier Ltd. All rights reserved.
\end{abstract}

Keywords: Kyoto Protocol; Industry; Energy; $\mathrm{CO}_{2}$ emissions

\section{Introduction}

The Kyoto Protocol was adopted in December 1997 at the third Conference of the Parties to the United Nations Framework Convention on Climate Change, setting limits on the greenhouse gas (GHG) emissions of industrialized countries $^{1}$. Under the Protocol, the European Union (EU) agreed to reduce its emissions of GHG by $8 \%$ during the period 2008-2012 in comparison to their 1990 levels. Subsequently, on June 1998, this target was reallocated internally, such that differences in the starting point, economic structure and available technologies would be

\footnotetext{
* Corresponding author. Tel.: +351 234400 800; fax: +351 234382876 E-mail address: borrego@ua.pt (C. Borrego).

${ }^{1}$ The six greenhouse gases covered by the Kyoto Protocol are: carbon dioxide $\left(\mathrm{CO}_{2}\right)$, methane $\left(\mathrm{CH}_{4}\right)$, nitrous oxide $\left(\mathrm{N}_{2} \mathrm{O}\right)$, hydrofluorocarbons $(\mathrm{HFC})$, per fluorocarbons $(\mathrm{PFC})$ and sulphur hexafluoride $\left(\mathrm{SF}_{6}\right)$.
}

taken in to account in a scheme known as 'burden-sharing'. In this context, Portugal was allowed to increase its GHG emissions by $27 \%$ in comparison to 1990 levels (Council of the European Union, 1998), which taking into account the six GHG balance corresponds to an increase of $40 \%$ in $\mathrm{CO}_{2}$ emissions (Portuguese Ministry of the Environment, 1997).

The Protocol also introduced three flexible mechanisms essential to its implementation: the international GHG Emissions Trading, the Joint Implementation (JI) and the Clean Development Mechanism (CDM). Emissions' trading is a scheme whereby companies are allocated allowances for their emissions of GHG, which they can trade subsequently with each other; the total of these allowances allocated to all companies included in the scheme represents the overall limit of emissions allowed by the scheme (COM, 2000). JI and CDM enable the Parties to the Protocol to meet part of their targets by taking advantage of opportunities to reduce 
GHG emissions in other countries at lower cost than at home (more details on these mechanisms can be found in the Appendix).

In July 2003, arising from the need of the EU to reduce its emissions of GHG cost-effectively, the European Council approved a Directive establishing a scheme on GHG emission allowance trading (Directive 2003/87/EC, 2003). The EU trading scheme will come into operation from 1 January 2005 and will initially run for a 3-year period until 31 December 2007. During the first period trading will only include $\mathrm{CO}_{2}$ emissions from the activities listed in the Directive's Annex I:

- combustion installations (exceeding $20 \mathrm{MW}$ );

- mineral oil refineries and coke ovens;

- production and processing of ferrous metals (including metal ore, pig iron and steel);

- mineral industry (cement clinker, glass and ceramics);

- industrial plants for the production of pulp, paper and board (with production capacity exceeding $20 \mathrm{t}$ per day).

Following this initial 3-year period, the scheme will operate over subsequent 5-year periods. Member states will have the option of including other GHG and additional industrial sectors in the trading scheme, in accordance with the provisions laid down in the Directive. For each of these periods, each member state shall develop a National Allocation Plan (NAP) stating the total quantity of allowances that it intends to allocate for that period and how it proposes to allocate them among the activities included in the trading scheme.

The aim of this paper is to contribute to the understanding of the present situation of the Portuguese transforming industry facing the Kyoto Protocol and the emissions trading Directive. An analysis of the $\mathrm{CO}_{2}$ emissions from different industry sectors in the 1990-2001 period and the projection for the 2002-2012 period is performed. The projected $\mathrm{CO}_{2}$ emissions for each sector are analysed in order to verify the accomplishment of the Kyoto Protocol. Furthermore, the $\mathrm{CO}_{2}$ emission projections are compared with the Portuguese NAP emission allowances (Portuguese Ministry of Economy and Ministry of the Cities, Planning and Environment, 2004).

The industry sectors analysed in this paper are: ceramics, pulp and paper, glass and cement clinker, which correspond to the Portuguese transforming industries included in the Directive's Annex I. These sectors are of great importance in the Portuguese economy and are responsible for $12 \%$ of total national $\mathrm{CO}_{2}$ emissions. Although Annex I from the Directive distinguishes different production capacities in industry installations, that distinction will not be done in this study due to lack of appropriate statistical information. However, this does not constitute a problem since small installations are responsible for less than $10 \%$ of the production.

\section{Methodology}

\section{1. $\mathrm{CO}_{2}$ emissions in the period 1990-2001}

The methodology adopted for $\mathrm{CO}_{2}$ emissions calculation follows the procedures contained in the Directive's Annex IV and the "International Panel for Climate Change" (IPCC) guidelines (IPCC, 1997). According to Annex IV, $\mathrm{CO}_{2}$ emissions from biomass burning are not accountable, neither indirect emissions from electricity consumption since the Directive refers only to direct emissions. Besides the emissions resulting from the combustion of fossil fuels, the $\mathrm{CO}_{2}$ emissions resulting from the production process itself will also be taken into account.

The $\mathrm{CO}_{2}$ emissions (tonnes) resulting from fossil fuels combustion were calculated according to the equation:

$$
\begin{aligned}
\mathrm{CO}_{2} \text { emissions }\left(\mathrm{t}_{\mathrm{CO}_{2}}\right)= & \text { fossil fuel consumption }(\mathrm{TJ}) \\
& \times \text { emission factor }\left(\mathrm{t}_{\mathrm{CO}_{2}} \times \mathrm{TJ}^{-1}\right) \\
& \times \text { oxidation factor }
\end{aligned}
$$

which was applied separately to each activity sector and each fuel type (TJ is an energy unit equal to $10^{12}$ joules). The data relating to fossil fuel combustion was obtained from the National Energy Accounts, except for the pulp and paper industry where values from the national paper industry association (CELPA) were used since the values from the National Energy Accounts are highly underestimated (CELPA, 2002). The emission factors are those presented in Table 1.

The $\mathrm{CO}_{2}$ emitted by the production process results from the decomposition of carbonated raw materials and from the consumption of chemical products used as additives. The calculation of these emissions is different for each industry sector:

- Cement industry: $\mathrm{CO}_{2}$ emissions from the process result from the use of carbonated raw materials and were calculated according to the equation:

$$
\begin{aligned}
& \mathrm{CO}_{2} \text { emissions }\left(\mathrm{t}_{\mathrm{CO}_{2}}\right) \\
& =\text { cement production }\left(\mathrm{t}_{\text {cement }}\right) \\
& \quad \times \text { emission factor }\left(\mathrm{t}_{\mathrm{CO}_{2}} \times \mathrm{t}_{\text {cement }}^{-1}\right)
\end{aligned}
$$

Table 1

Emission factors (IPCC, 1997).

\begin{tabular}{lc}
\hline Fuel & Emission factors $\left(t_{\mathrm{CO}_{2}} \mathrm{TJ}^{-1}\right)$ \\
\hline Anthracite & 98.3 \\
Petroleum coke & 100.8 \\
LPG & 63.1 \\
Gasoline & 69.3 \\
Crude oil & 73.3 \\
Gas/diesel oil & 74.1 \\
Lubricants & 73.3 \\
Natural gas & 56.1 \\
\hline
\end{tabular}


with the cement production data and the emission factor $\left(0.446 \mathrm{t}_{\mathrm{CO}_{2}} / \mathrm{t}_{\text {cement }}\right)$ provided by the Portuguese Cement Industry Technical Association.

- Ceramics industry: $\mathrm{CO}_{2}$ emissions from the process are not significant.

- Glass industry: The main $\mathrm{CO}_{2}$ emissions from the process result from the use of carbonated raw materials. Due to lack of statistical data on raw material consumption that would allow the use of emission factors, data from one of the main Portuguese glass producers (Barbosa and Almeida, 2002), which indicates a contribution of $30 \%$ from the production processes on total glass production $\mathrm{CO}_{2}$ emissions, was used.

- Pulp and paper industry: The main $\mathrm{CO}_{2}$ emissions from the process result from the use of chemical products (calcium and sodium carbonate) in the pulp production and were calculated according to the equation:

$$
\begin{aligned}
\mathrm{CO}_{2}\left(\mathrm{t}_{\mathrm{CO}_{2}}\right) & =\mathrm{CaCO}_{3}(\mathrm{t}) \times \text { emission factor }\left(\mathrm{t}_{\mathrm{CO}_{2}} \times \mathrm{t}_{\mathrm{CaCO}_{3}}^{-1}\right) \\
& +\mathrm{Na}_{2} \mathrm{CO}_{3}(\mathrm{t}) \times \text { emission factor }\left(\mathrm{t}_{\mathrm{CO}_{2}} \times \mathrm{t}_{\mathrm{Na}_{2} \mathrm{CO}_{3}}^{-1}\right)
\end{aligned}
$$

with the emission factors from the "National Council of the Paper Industry for Air and Stream Improvement" (NCASI, 2002) and chemical products consumption from the Portuguese National Statistics Institute.

\section{2. $\mathrm{CO}_{2}$ emissions projection for the period 2002-2012}

In order to estimate $\mathrm{CO}_{2}$ emissions, the first step was to calculate energy consumption for the period 2002-2012. It took into account the projection of the gross value added (GVA) for Portugal given by the Ministry of Economy (GEPE, 2002), which considered two possible development scenarios:

- Low economic scenario: improvement of the competition capacity through an increase in productivity and a commitment in the binomial price/quality.

- High economic scenario: wide expansion of the industry strategy in the foreign market, through a larger capacity for innovation.

Table 2 presents the GVA projections for each industry sector analysed and for each economic scenario.

With the aim of establishing a baseline energy scenario for energy consumption from the GVA projections, it was assumed that for the period 2002-2012, the value of the energy intensity (i.e., the energy consumption by GVA unit) would be the same as in 2001. The fuel mix of each industry was assumed constant between 2002 and 2012 and equal to that in 2001. For each industry sector, the projection of the base consumption of energy for each year of the period 2002-2012, was calculated according to the equation:
Table 2

GVA average annual growth (\%) (GEPE, 2002).

\begin{tabular}{lll}
\hline Industry sectors & $\begin{array}{l}\text { Low economic } \\
\text { scenario } \\
(2000-2015)\end{array}$ & $\begin{array}{l}\text { High economic } \\
\text { scenario } \\
(2000-2015)\end{array}$ \\
\hline Cement & 3.5 & 2.0 \\
Ceramics & 3.7 & 2.5 \\
Glass & 3.5 & 2.0 \\
Pulp and paper & 4.0 & 3.0 \\
\hline
\end{tabular}

Energy consumption $\left._{i}(\mathrm{TJ})=\operatorname{energy~}_{\text {intensity }} \operatorname{coo0}_{2 \mathrm{TJ}} €^{-1}\right)$

$$
\times \mathrm{GVA}_{i}(€)
$$

To allow the construction of emission reduction scenarios, a report produced for the European Commission by “AEA Technology Environment"(1999), analysing the industry energetic situation in Portugal, among other EU countries, was used to help estimate the energy consumption reduction potential, and consequently the $\mathrm{CO}_{2}$ emission reduction potential. In this report, technology cost-supply curves are defined for each of the industry sectors analysed, establishing the priority in terms of options to reduce energy consumption. The technology cost-supply curves illustrate the energy savings potential of different technologies as a function of its specific costs (in monetary units) per unit of energy saved (GJ). Two sets of criteria have been adopted to identify cost effective technologies under:

- normal industrial investment requirements (25\% discount rate and 5 year depreciation);

- strategic national investment criteria (4\% discount rate and technical lifetime).

The annual cost-effective energy savings for each industry sector, considering the two sets of investment criteria, are presented in Table 3.

Summarising, the present work analyses, for each of the economic scenarios (high and low), three possible energy scenarios:

- baseline energy scenario: calculated through Eq. (4);

- normal investment energy scenario: introduction of energy consumption reduction technologies, considering normal investment criteria;

Table 3

Annual cost-effective energy savings (PJ year ${ }^{-1}$ ) (AEA Technology Environment, 1999)

\begin{tabular}{llc}
\hline Industry sectors & $\begin{array}{l}\text { Normal } \\
\text { investment criteria }\end{array}$ & $\begin{array}{l}\text { Strategic } \\
\text { investment criteria }\end{array}$ \\
\hline Cement & 3.1 & 6.1 \\
Ceramics & 1.7 & 4.3 \\
Glass & 6.0 & 8.2 \\
Pulp and paper & 7.0 & 17.0 \\
\hline
\end{tabular}


- strategic investment energy scenario: introduction of energy consumption reduction technologies, considering strategic investment criteria.

For the normal and strategic investment criteria, the energy consumption estimations were derived from the baseline energy scenario, subtracting the saved energy from total energy.

The $\mathrm{CO}_{2}$ emissions projection resulting from fossil fuels combustion was estimated according to Eq. (1), using the three energy consumption scenarios estimated.

The $\mathrm{CO}_{2}$ emissions coming from the production process for the period 2002-2012 were calculated from the $\mathrm{CO}_{2}$ emissions from the fossil fuels emissions, assuming that the proportion of these emissions in relation to the total $\mathrm{CO}_{2}$ emissions would remain constant until 2012, in reference to the year 2001 .

\section{Results and discussion}

\subsection{Period 1990-2001}

Fig. 1 presents the energy consumption for each of the industry sectors studied. It shows the pulp and paper industry as the major energy consumer, with almost 54,000 TJ in 2001. The cement and ceramics industries present similar consumption values, around 37,000 TJ in 2001. Although the glass industry shows energy consumptions significantly smaller, reaching $11,000 \mathrm{TJ}$ in 2001 , it presents the greatest growth between 1990 and 2001 (84\%). The cement industry was the sector with the smallest energy consumption growth in the same period (37\%), while ceramics and the pulp and paper industries present growths of 56 and 67\%, respectively.

Since the fuel-mix assumes special importance in the $\mathrm{CO}_{2}$ emissions quantification, Fig. 2 shows the fuel-mix for 1990, 1995 and 2001. The cement and the glass industries exhibit an important dependence on fossil fuels, while the ceramics and the pulp and paper production present a significant share of biomass as energy source. Regarding the fuel-mix over the analysed period, the cement industry presents a clear substitution of coal by pet-coke, a petrol derivate; in ceramics, the biomass share decreased from $53 \%$ in 1990 to $37 \%$ in 2001 , due to the fuel shift to natural gas; between 1990 and 1995 the glass industry maintained its fuel mix, while in 2001 natural gas surpassed the petrol derivates as the main energy source; the fuel mix of the pulp and paper industries has been constant over the years, with biomass as the main energy source and a small contribution of natural gas appearing in 2001.

The fuel mix differences are reflected on the industries' $\mathrm{CO}_{2}$ emissions, as can be seen in Fig. 3, which presents the total $\mathrm{CO}_{2}$ emissions for each of the industry sectors studied. The cement industry presents the highest level of $\mathrm{CO}_{2}$ emissions, with a growth of $31 \%$ between 1990 and 2001, reaching near $7000 \mathrm{kt}$ in 2001. The other industry sectors produce much less $\mathrm{CO}_{2}$ : in 2001 the ceramics, glass and the pulp and paper sectors reached 1225,870 and $871 \mathrm{kt}$, respectively. The pulp and paper $\mathrm{CO}_{2}$ emissions have grown $150 \%$ between 1990 and 2001, while the ceramics and glass industries present growths of 86 and $51 \%$, respectively.

Fig. 4 shows the share of $\mathrm{CO}_{2}$ emissions from fossil fuels and from the production process for 2001; in the cement industry, the production process originates almost $60 \%$ of the emissions, while in the other industries fossil fuel burning is the main source of $\mathrm{CO}_{2}$.

\subsection{Period 2002-2012}

Figs. 5-7 show the energy consumption estimated for 2002-2012, for the baseline energy scenario, the normal investment energy scenario and the strategic investment energy scenario, respectively. For all the scenarios, the pulp and paper industry presents the highest growth in energy consumption with values ranging from 57 to 83 GJ in 2012 . The cement and ceramics industries present similar energy consumption levels, around 50 GJ. The glass industry shows the biggest differences between scenarios, reaching in the strategic energy scenario for 2012 values lower then those of 2001 .

Table 4 presents the $\mathrm{CO}_{2}$ emissions estimated for 20022012 for the three energy scenarios. The cement industry is clearly the sector with the larger $\mathrm{CO}_{2}$ emissions, between 7500 and $10,200 \mathrm{kt}$ in 2012, largely due to the high emissions coming from the raw materials processing. The

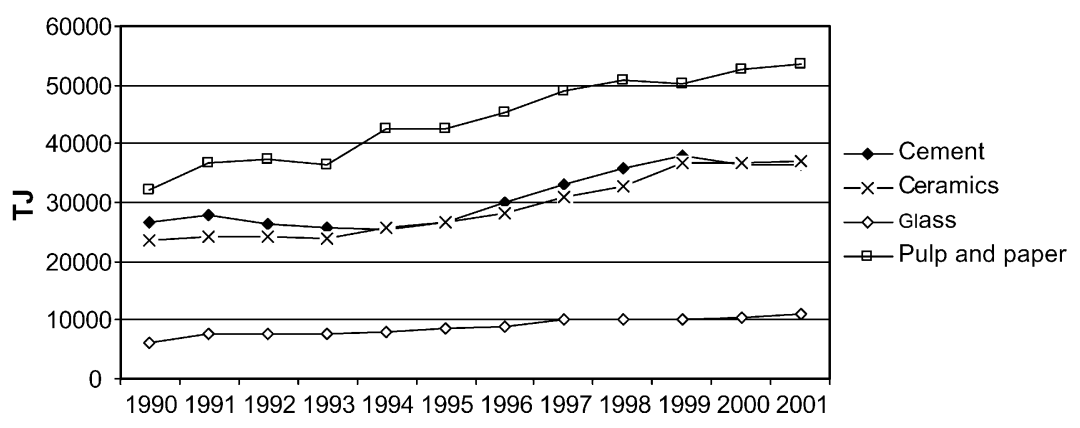

Fig. 1. Energy consumption in the period 1990-2001. 


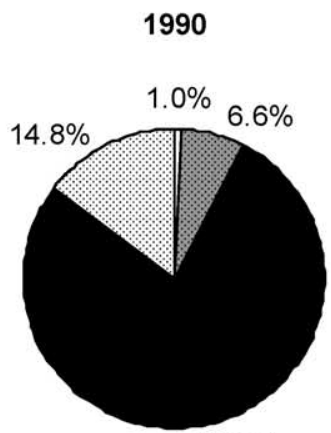

$77.7 \%$

(a) Cement

1990

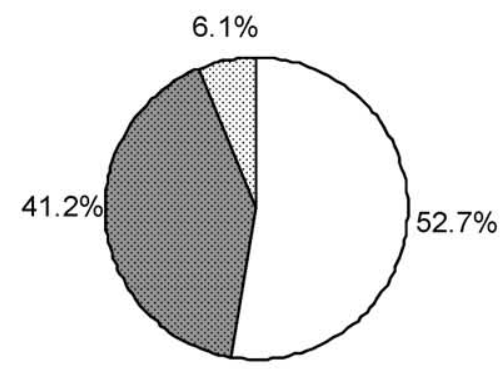

(b) Ceramics

1990

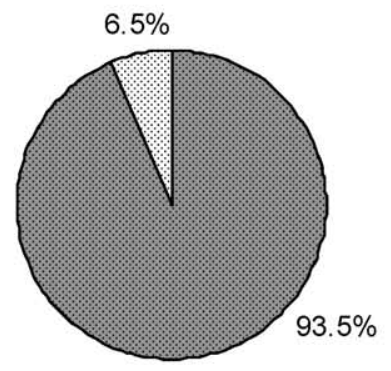

(C) Glass

1990

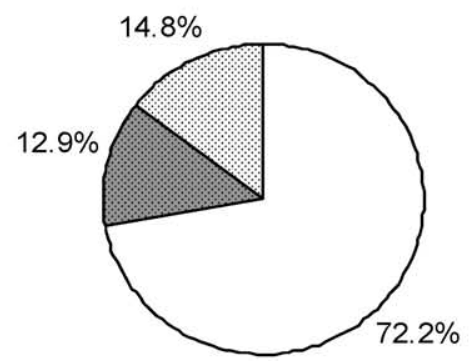

(d) Pulp and paper

$\square$ Biomass

(d) Pulp and paper
1995

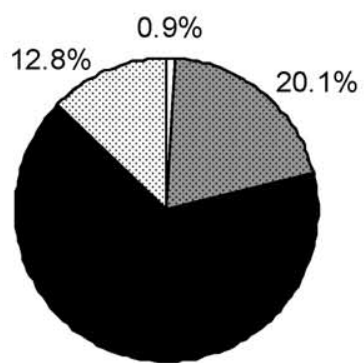

$66.1 \%$

1995

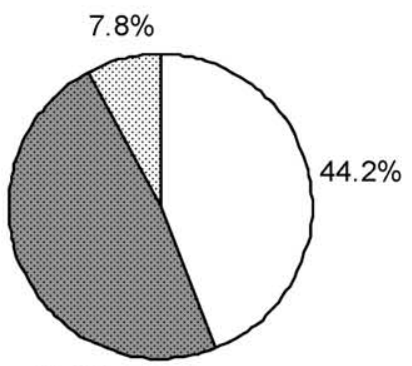

$47.9 \%$

1995

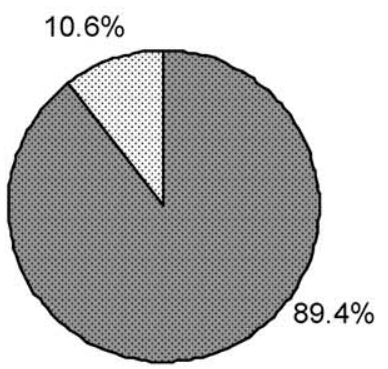

1995

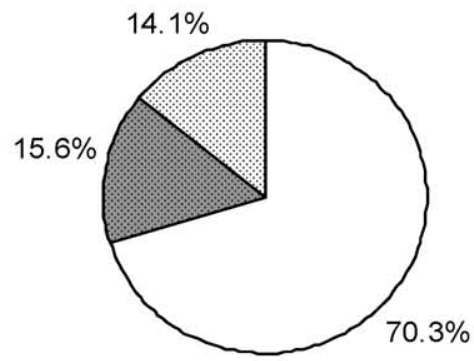

$70.3 \%$

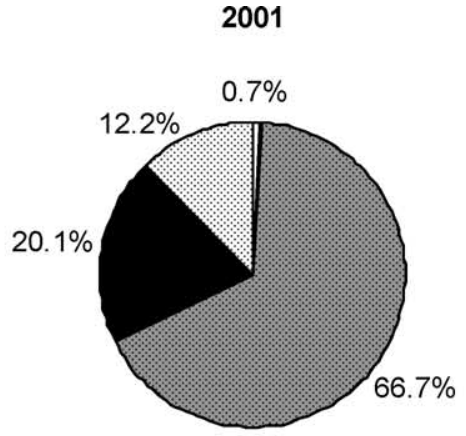

2001

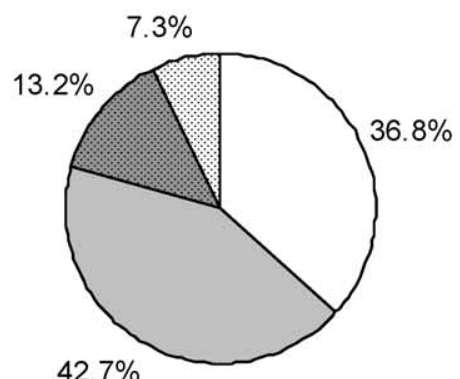

2001

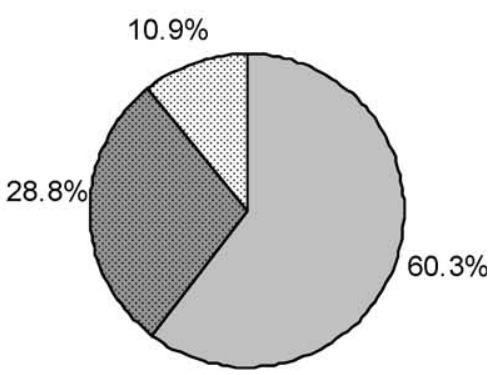

2001

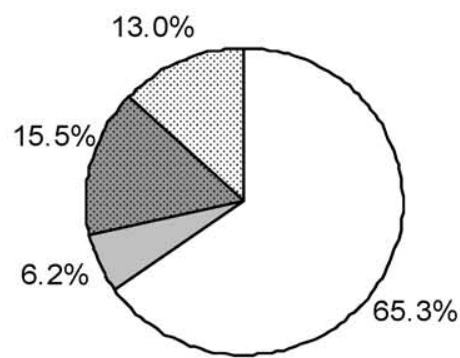

Natural gas

Petrol

Coal

Electricity

Fig. 2. Fuel-mix for 1990, 1995 and 2001. 


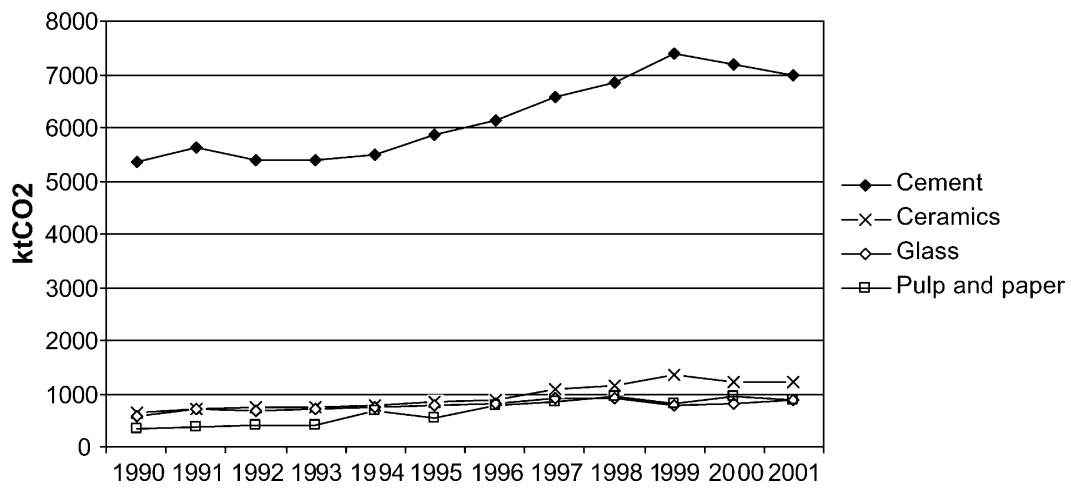

Fig. 3. $\mathrm{CO}_{2}$ emissions in the period 1990-2001.

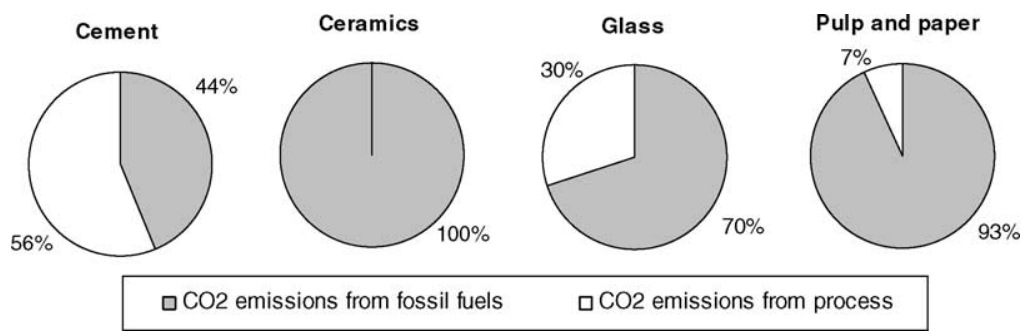

Fig. 4. $\mathrm{CO}_{2}$ emissions share for 2001 .

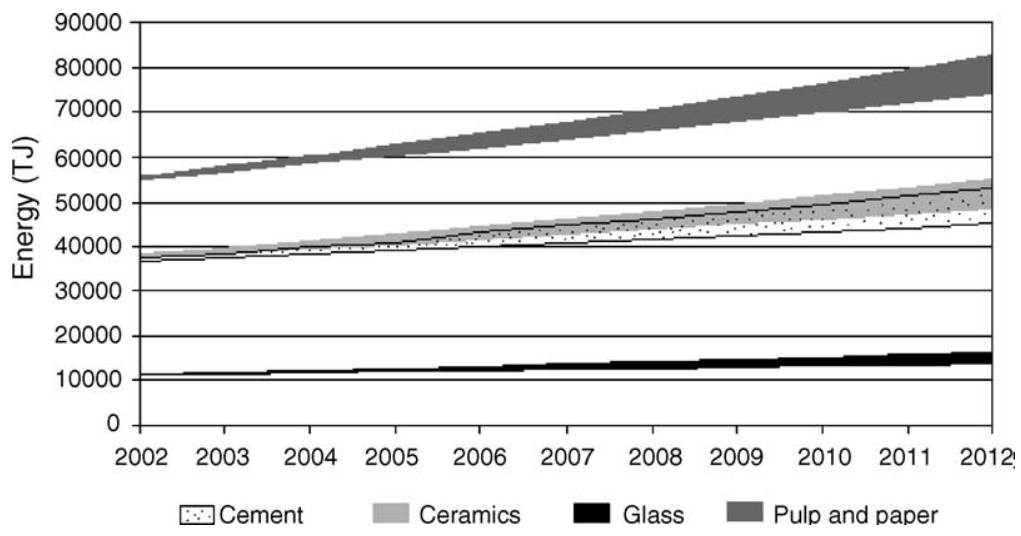

Fig. 5. Energy consumption estimation for the base energy scenario.

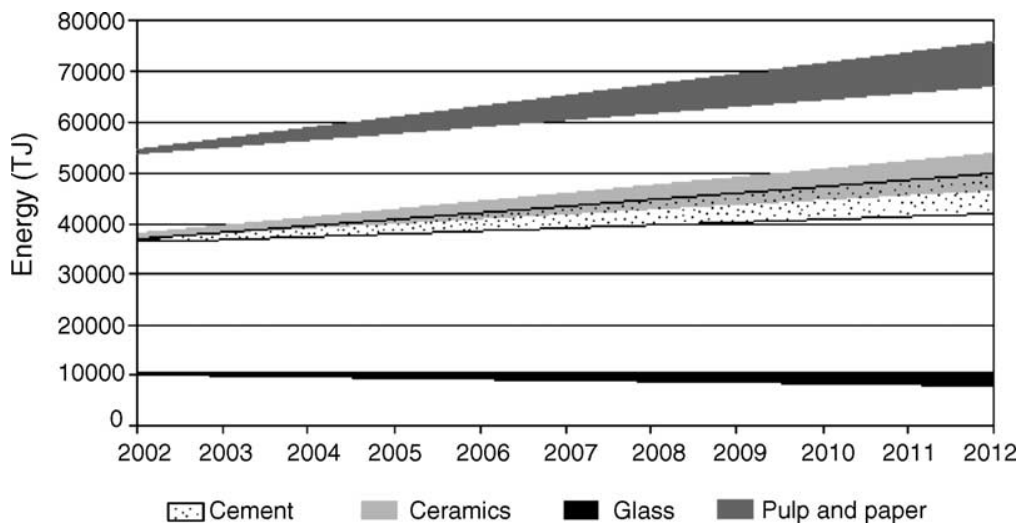

Fig. 6. Energy consumption estimation for the normal investment energy scenario. 


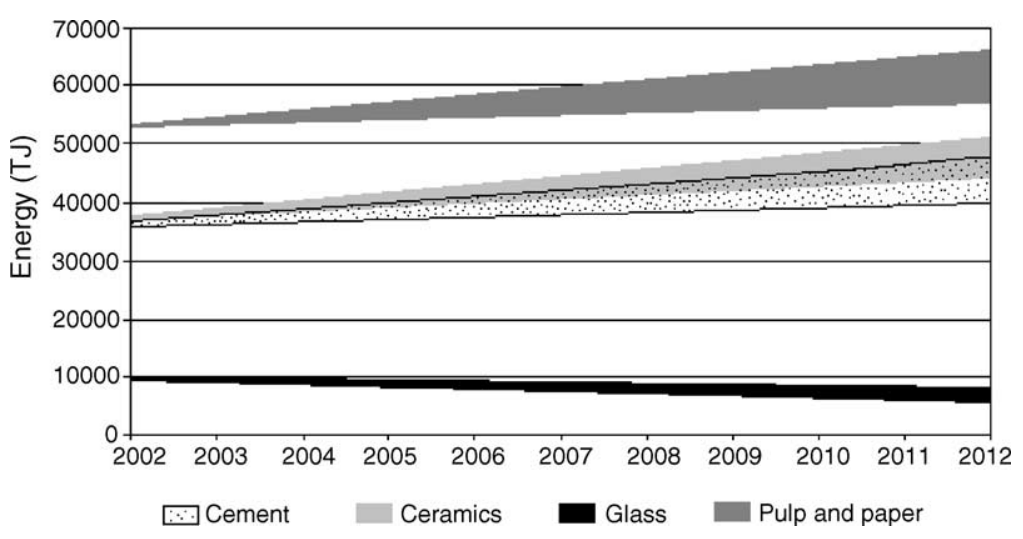

Fig. 7. Energy consumption estimation for the strategic investment energy scenario.

Table 4

$\mathrm{CO}_{2}$ emissions (kt) estimated for 2002-2012

\begin{tabular}{llcc}
\hline Industry sectors & Base energy scenario & Normal investment energy scenario & Strategic investment energy scenario \\
\hline Cement & $8690-10204$ & $8094-9608$ & $7517-9266$ \\
Ceramics & $1607-1827$ & $1551-1770$ & $1465-1684$ \\
Glass & $1082-1270$ & $611-799$ & $438-627$ \\
Pulp and paper & $1204-1339$ & $1091-1226$ & $929-1064$ \\
\hline
\end{tabular}

ceramics industry is the second largest emitter with values around 1500 and $1800 \mathrm{kt}$. Although it is the larger energy consumer, the pulp and paper industry $\mathrm{CO}_{2}$ emissions are only $12 \%$ of the cement industry emissions, since $65 \%$ of its energy consumption comes from biomass, a neutral fuel in terms of $\mathrm{CO}_{2}$. The glass industry presents the lower $\mathrm{CO}_{2}$ emission levels.

Figs. 8-10 show the $\mathrm{CO}_{2}$ emissions growth in relation to 1990, estimated for 2002-2012, for each of the studied sectors. Fig. 8 shows that for the baseline energy scenario, i.e. without any energy efficient technology introduction, none of the industry sectors will be able to fulfil the $40 \%$ limit growth. It is also possible to observe that the pulp and paper industry presents the highest $\mathrm{CO}_{2}$ growth (between 250 and $290 \%$ ), while the cement industry presents the lowest growth (between 60 and 90\%). Figs. 9 and 10 show that the glass industry presents the largest $\mathrm{CO}_{2}$ reduction potential, being the only sector to grow below $40 \%$, and even emit less $\mathrm{CO}_{2}$ in 2012 in relation to 1990, in the strategic scenario. The pulp and paper industry also presents, in the strategic energy scenario, an interesting $\mathrm{CO}_{2}$ reduction potential but not sufficient to grow below $170 \%$. The cement and ceramics industry present low $\mathrm{CO}_{2}$ reduction potentials, with minimum growths of 41 and $123 \%$, respectively.

\subsection{The portuguese national allocation plan}

In accordance with the Directive on GHG emission trading, Portugal submitted in May 2004 the NAP (Portuguese Ministry of Economy and Ministry of the Cities, Planning and Environment, 2004) to the European Commission. The reference scenario from the Portuguese National Climate Change Programme (PNAC, 2002) was assumed to determine the total quantity of allowances to

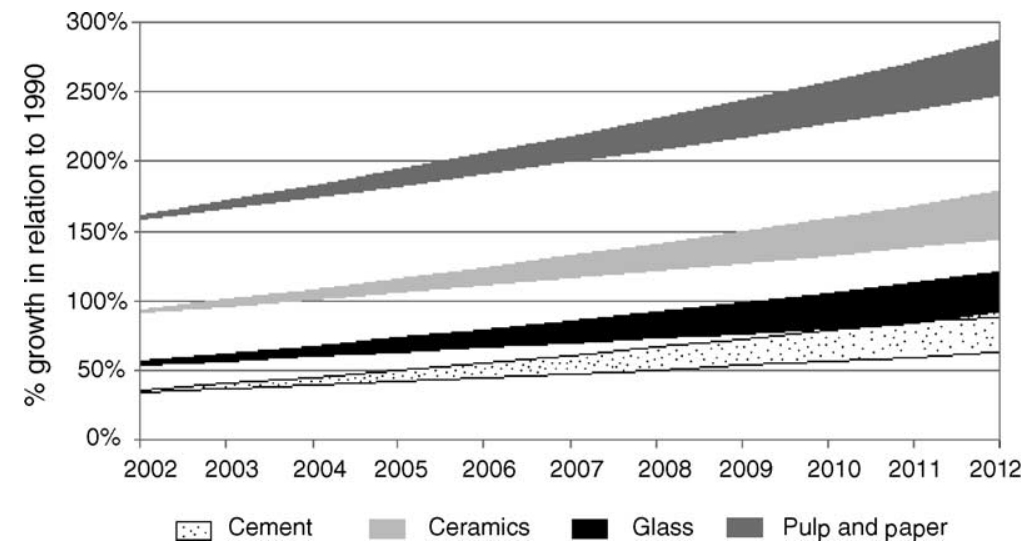

Fig. 8. $\mathrm{CO}_{2}$ emission growth estimation for the base energy scenario. 


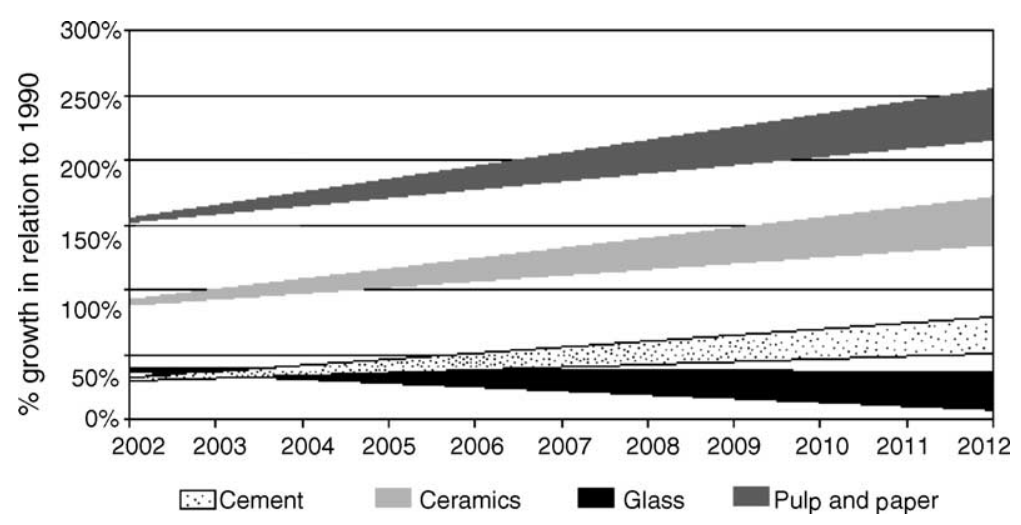

Fig. 9. $\mathrm{CO}_{2}$ emission growth estimation for the normal investment energy scenario.

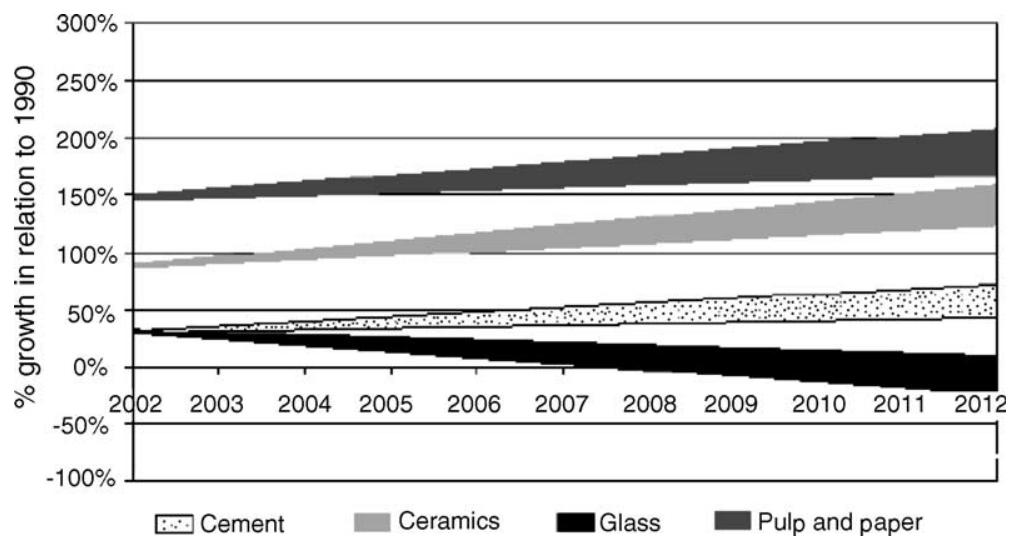

Fig. 10. $\mathrm{CO}_{2}$ emission growth estimation for the strategic investment energy scenario.

allocate to sectors covered by the Directive. The allocation of allowances by activity sector was based on the sum of historical emissions from installations or, in specific cases, on projections. The amount of allowances to allocate to each sector resulted from the sum of emissions calculated for each installation in the sector, multiplied by a global adjustment factor, allowing the accommodation of a marginal increase in capacity used by existing installations. The base criterion for emissions calculation per installation was the result, as a maximum value, of the average of the 2 years of higher emissions from the 3-year periods of 2000-2002 or 20012003.

In November 2003, the Portuguese Industry Confederation (CIP) released a document stating its position in relation to the Kyoto Protocol and the EU emission trade scheme (CIP, 2003). CIP states that in order to guarantee that the application of the Directive will not affect economic convergence and the industries sustainability in a significant way, the NAP should attribute around $38 \mathrm{Mt} \mathrm{CO}_{2}$ per year emissions free of licence charge for the period 2005-2007, necessary to cover the predicted emissions.

The proposed NAP met the CIP expectations allocating 116.6 Mt $\mathrm{CO}_{2}$ allowances (38.9 $\mathrm{Mt} \mathrm{CO}_{2}$ year $^{-1}$ ), free of charge, for the period 2005-2007 to the sectors covered by the Directive.

Fig. 11 presents a comparison between the $\mathrm{CO}_{2}$ projections and the Portuguese NAP $\mathrm{CO}_{2}$ allowance proposal for the industry sectors under study. The values
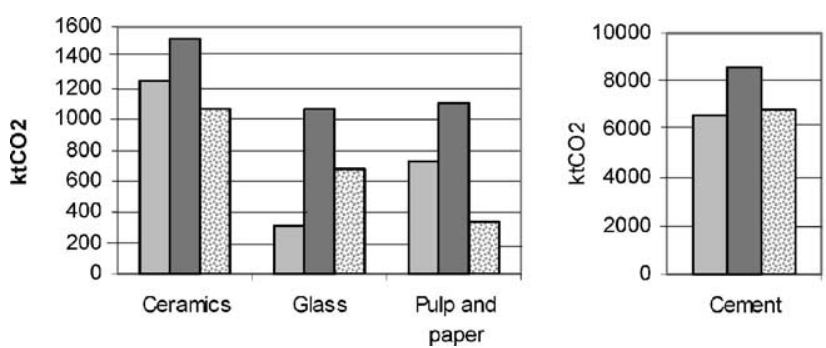

口Estimated low

$\square$ Estimated high

$\square N A P$

Fig. 11. Comparison between $\mathrm{CO}_{2}$ projections and the Portuguese $\mathrm{NAP} \mathrm{CO}_{2}$ allowance proposal. 
are similar except for $\mathrm{CO}_{2}$ emissions from the pulp and paper industry. This fact can be explained due the fact that the projections and the NAP calculations are based on different energy consumption data sources: the National Paper Industry (CELPA, 2002) and the National Energy Accounts, respectively.

\section{Conclusions}

All the sectors present in a "business as usual" scenario, a significant growth in energy consumption and, consequently, in $\mathrm{CO}_{2}$ emissions in the period 1990-2012. In fact, between 1990 and 2001, $\mathrm{CO}_{2}$ emissions have grown above the $40 \%$ limit in all industry sectors $(86,51$ and $150 \%$ for ceramics, glass and pulp and paper, respectively) except for cement (31\% growth). This increase compromised greatly the estimations for 2012, even in the most favourable slowgrowing economy with a strategic energy scenario.

The glass sector presents itself as the only sector able to grow below the $40 \%$ limit until 2012, due to its significant energy reduction potential. In the context of the emission trading mechanism, the glass industry appears as a future $\mathrm{CO}_{2}$ emission allowance seller, provided the investment in energy efficient technologies.

The pulp and paper industry appears in a very unfavourable position; despite presenting the greatest cost-effective energy savings and a major contribution of biomass in its fuel mix, in the most favourable scenario the $\mathrm{CO}_{2}$ emissions will grow $170 \%$, in part due to the enormous growth that occurred in the 1990-2001 period.

The cement and ceramics industries present small energy consumption reduction potential, meaning that almost all the cost-effective energy saving technologies have already been implemented. In these two sectors, measures other than energy efficient technologies will have to be implemented to reduce $\mathrm{CO}_{2}$ emission growth such as fuel switching and, in the particular case of the cement industry, the production of cement with lower clinker content. Cement production assumes a special importance since its $\mathrm{CO}_{2}$ emission levels are five to eight times bigger than the other sectors.

In the framework of the market mechanisms established by the Kyoto Protocol, these three sectors (cement, ceramics and pulp and paper), as potential $\mathrm{CO}_{2}$ emission allowance buyers, should consider alternative strategies such as JI and CDM. In fact, the Portuguese Industry Confederation (CIP) defends in its position paper that these mechanisms are essential to cover the emission deficit estimated for 20082012 (CIP, 2003). CIP considers that, following the example from other EU countries, a "Carbon Fund" should be established allowing the country to cover the emission deficit in the most economic efficient way. The process would take place through direct investment in JI/CDM projects, which the Fund would finance. This fund would serve as an external policy instrument promoting also the sustainable development in developing countries.
The industry considers that the "Carbon Fund" should be financed by the national government since they consider that during the EU "burden-sharing" negotiations "Portugal agreed on a highly ambitious and unrealistic objective" (CIP, 2003). Portugal negotiated the lowest $\mathrm{CO}_{2}$ emissions per capita in the $\mathrm{EU}\left(7.6 \mathrm{t}_{\mathrm{CO}_{2} \mathrm{eq}}\right)$, significantly below the $\mathrm{EU}$ average objective $\left(10 \mathrm{t}_{\mathrm{CO}_{2} \mathrm{eq}}\right)$ and also because sectors outside the Directive will grow more than $100 \%$ during the 1990-2012 period, creating difficulties for Portugal under the Kyoto Protocol.

\section{Acknowledgments}

The authors wish to thank the third EU Framework Program for financial support and the Portuguese Ministério da Ciência e do Ensino Superior, for the Ph.D. grants of H. Martins (SFRH/BD/13581/2003) and M. Lopes (PRAXIS $\mathrm{XXI} / \mathrm{BD} / 13756 / 97)$. The authors would also like to thank to the Portuguese Cement Industry Technical Association (ATIC) for the information provided.

\section{Appendix A.}

\section{A.1. Kyoto's market-based flexible mechanisms}

The Kyoto Protocol envisages three market-based "flexible mechanisms": Emissions Trading, Joint Implementation (JI) and Clean Development Mechanisms (CDM). These will to allow industrialised countries to meet their targets through trading emission allowances between themselves and gaining credits for emission-curbing projects abroad.

The rationale behind these three mechanisms is that GHG are a global problem and that the place where reductions are achieved is of less importance. In this way, reductions can be made where costs are lowest, at least in the initial phase of combating climate change.

\section{A.2. Emissions trading}

While the implementation of the three flexible mechanisms at international level will become possible only once the Kyoto Protocol comes into force, the EU is moving ahead with its own internal emissions trading system. The EU scheme will be the first multi-national emissions trading scheme in the world and is considered a forerunner of the international emissions trading scheme under the Kyoto Protocol.

Under the EU emissions trading scheme, the EU Member States will set limits on $\mathrm{CO}_{2}$ emissions from energyintensive industries by issuing allowances as to how much $\mathrm{CO}_{2}$ these industries are allowed to emit. Industries that achieve reductions can sell them to companies that have problems staying within their limits or for which emissions 
reduction measures are too expensive in comparison with what the allowances will cost. Any industry may also increase its emissions above the level of allowance it is issued by acquiring more allowances from the market. This scheme will induce companies to make emission cuts where they are cheapest, thereby ensuring that reductions are made at the lowest possible cost to the economy and also that innovation is fostered.

The EU has also indicated its willingness to link the EU scheme to trading schemes in other countries that have ratified the Kyoto protocol.

\section{A.3. Joint implementation and the clean development mechanism}

Under the Kyoto Protocol, Joint Implementation (JI) and the Clean Development Mechanism (CDM) will allow industrialised countries to achieve part of their emission reduction commitments by conducting emission-reducing projects abroad and counting the reductions achieved toward their own commitments. JI will allow for projects in other industrialised countries with Kyoto targets, while CDM will take place in countries without targets, i.e. developing countries. A condition for the issue of credits in respect of the reductions achieved is that the projects result in real, measurable and long-term climate change benefits.

Building on these provisions and the EU emissions trading system, the Commission adopted on July 2003 a proposal that links credits from JI and CDM projects with the emissions trading system. Under this proposal, European industries covered by the EU emissions trading system will be allowed to convert credits from JI and CDM projects for use towards meeting their commitments under the trading system. Governments will also be allowed to use credits from JI and CDM projects towards meeting their commitments under the Kyoto Protocol during the first commitment period 20082012, provided that the Protocol enters into force.

\section{References}

AEA Technology Environment, 1999. Detailed Modelling of the Priority of Industrial Energy Efficiency Technologies for Europe. European Commission, UK.

Barbosa, Almeida, 2002. Relatório Ambiental 2001 (Environment Report 2001). B\&A, Portugal.

CELPA-Associação da Indústria Papeleira (Portuguese Paper Industry Association), 2002. Boletim Estatístico de 2001 (2001 Statistical Bulletin). CELPA, Portugal.

CIP (Portuguese Industry Confederation), 2003. Os desafios do Protocolo de Kyoto e da Directiva de Comércio de Emissões-Posição da Indústria
Portuguesa (Kyoto Protocol Challenges and The Emission Trading Directive-Position of the Portuguese Industry), CIP, Portugal.

COM (2000) 87 final, 2000. Green Paper on Greenhouse Gas Emissions Trading within the European Union. European Commission, Brussels. Council of the European Union, 1998. Community Strategy on Climate Change-Council Conclusions Nr. 9402/98. European Commission, Brussels.

Directive 2003/87/EC of the European Parliament and of the Council Establishing a Scheme for Greenhouse Gas Emissions Allowance Trading within the Community and Amending Council Directive 96/ 61/EC, Official Journal of the European Union, Brussels, pp. L 275/32L 275/46, 2003.

GEPE, 2002. Cenários para a Economia Portuguesa 2000-2025 (Scenarios for the Portuguese Economy 2000-2025). Ministry of Economy, Portugal.

IPCC, 1997. Houghton, J.T., Meira Filho, L.G., Lim, B., Tréanton, K., Mamaty, I., Bonduki, Y., Griggs, D.J., Callander, B.A. (Eds.), Greenhouse Gas Inventory Workbook. Bracknell.

NCASI, 2002. Calculation Tools for Estimating Greenhouse Gas Emissions from Pulp and Paper Mills. The International Council of Forest and Paper Associations, USA.

Portuguese Ministry of Economy and Ministry of the Cities, Planning and Environment, National Allocation Plan for $\mathrm{CO}_{2}$ Emission AnalysisVersion to the European Commission, Portugal, 2004.

Portuguese Ministry of the Environment, Portugal Second Report to be submitted to the Conference of Parties to the Framework Convention on Climate Change, 1997.

Portuguese National Climate Change Programme (PNAC), Climate Change Commission, Portugal, 2002.

Carlos Borrego is professor of environmental engineering, with focus on Air Pollution and Energy and Environment. He has the habilitation on applied environmental sciences from the University of Aveiro, $\mathrm{PhD}$ and MSc from the Free University of Brussels and a degree in mechanical engineering from the Technical University of Lisbon. Currently, he is the scientific co-ordinator of five projects under sixth FP of EC Environment and Sustainable Development Programme and four projects under the National Funding Agency. He is also Chairman of the Scientific Board of International Technical Meetings of NATO-CCMS on Air Pollution Modelling and its Application and was vice-chairman of the Environmental Assessment Group of EUROTRAC-2 (EUREKA Environmental Project), from 1997 to 2000 .

Helena Martins is a PhD student in sciences applied to the environment at the University of Aveiro. She has a master of science degree on economics and politics of energy and environment and a degree on environmental engineering. Currently, she is part of the Research Group on Emissions, Modelling and Climate Change (GEMAC). Her research interests include air pollution (emissions and modelling), environmental economics, climate change and urban air quality.

Myriam Lopes is invited assistant at Department of Environment and Planning at the University of Aveiro. She is an environmental engineer and has a master of science degree on air pollution. Currently, she is finishing her $\mathrm{PhD}$ on climate change and the use of economic instruments to mitigate greenhouse gases emissions in Portugal, working in the Research Group on Emissions, Modelling and Climate Change (GEMAC). Her research interests include environmental politics, atmospheric and energy modelling, environmental economics and pollution health effects. 